\title{
The effect of artificial sweeteners on body weight of mice
}

\author{
Iyad Ali, ${ }^{1}$ Naser Shraim, ${ }^{2}$ Wafaa' Atrash, ${ }^{2}$ Aisha Sirafi, ${ }^{2}$ Huda Abadi ${ }^{2}$ \\ ${ }^{1}$ Department of Biochemistry, Faculty of Medicine and Health Sciences, An-Najah National University, Nablus; \\ ${ }^{2}$ Department of Pharmacy, Faculty of Medicine and Health Sciences, An-Najah National University, Nablus, Palestine
}

\begin{abstract}
Artificial Sweeteners (AS) are synthetic sugar substitutes that have sweetening potency hundreds of times more than the table sugar (sucrose). Artificial sweeteners are regarded as attractive alternatives to sugar as they add no calories to food intake. There are many hypotheses suggesting that AS may enhance appetite and cause weight gain. The aim of this study was to evaluate the effect of AS on food intake, fluid intake and body weight of mice. Acceptable daily intakes of AS solutions were administered orally to different set of mice for four weeks. The body weight, food consumption and fluid intake were measured. At the same time, the effect of Zingiber officinale extracts (natural appetite suppressor), Thymus vulgaris extracts (natural appetite inducer) and cyprohep-
\end{abstract}

Correspondence: Iyad Ali, Department of Biochemistry, Faculty of Medicine and Health Sciences, An-Najah National University, Nabus, Palestine.

Fax: +97092345113

E-mail: iyadali@najah.edu

Acknowledgments: An-Najah National University is thankfully acknowledged for providing the labs to carry this study.

Key words: Artificial Sweeteners; body weight; mice; Zingiber officinale; Thymus vulgaris; cyproheptadine.

Contributions: IA, WA and HA conceived of the presented idea. IA, NS, AS and HA developed the theory and performed the computations. IA, NS, WA and AS verified the analytical methods. IA supervised the findings of this work. All authors discussed the results and contributed to the final manuscript.

Conflict of interest: The Authors declare no conflict of interest

Funding: This work was funded by the faculty of Medicine and Health Sciences at An-Najah National University, Nablus, Palestine.

Received for publication: 25 December 2019.

Accepted for publication: 23 March 2020.

${ }^{\circ}$ Copyright: the Author(s), 2020

Licensee PAGEPress, Italy

Journal of Biological Research 2020; 93:8783

doi:10.4081/jbr.2020.8783

This article is distributed under the terms of the Creative Commons Attribution Noncommercial License (by-nc 4.0) which permits any noncommercial use, distribution, and reproduction in any medium, provided the original author(s) and source are credited. tadine (an appetite stimulant drug) on body weight of mice was evaluated. Artificial sweeteners consumption cause insignificant changes in body weight ( $p>0.05)$. However, the mean consumption of food and solutions varies significantly for some groups. The consumption of AS has no significant effect on body weight and may contribute to weight maintenance and energy balance as substitutes to high caloric sugar.

\section{Introduction}

Excess consumption of sugars has been highlighted as a primary concern by the world health organization with new recommendations stating that individuals should reduce their intake of sugar to less than $10 \%$ of daily calories. ${ }^{1}$ This cause the food industry to produce several forms of alternative non-caloric and intense sweeteners, which have made it possible to give consumers the sweet taste with no calories.

Artificial Sweeteners (AS) are synthetic sugar substitutes and they have sweetening potency hundreds of times more than table sugar (sucrose). Therefore, AS regarded as attractive alternatives to sugar because they add no calories to our diet. ${ }^{2}$ Although all low caloric sweeteners are very sweet compounds, each of them is chemically different. Some provide no calories while others provide a very small amount, such as Aspartame, which is metabolized rapidly after ingestion, whereas Sucralose is not absorbed but excreted in the feces, and Saccharin is absorbed and excreted in the urine unchanged. ${ }^{3}$ All low caloric sweeteners mentioned above are approved by FDA for their safety.

In fact, such products are now widespread as sugar substitutes based on the premise that the use of these products as an alternative to sugar would result in decreased caloric intake, lead to weight loss, and decrease the incidence of diabetes mellitus, obesity, cardiovascular diseases and other diseases. Despite that, the rate of obesity has remained stable suggesting that AS are not an optimal tool for weight loss. ${ }^{4}$ Numerous hypotheses have been presented to explain that including those that involving ingestion of food or beverages with AS flavor triggers body systems to expect ingested energy and when the energy is not supplied an increase in appetite and subsequent food intake occur. ${ }^{5}$ Another hypothesis has been suggested that AS failed to activate SGLT-1 that is responsible for the secretion of satiety hormones. ${ }^{6}$

The effects of AS on food intake and body weight over longterm are still unclear. In our experiment, we studied the effect of the AS on appetite and body weight on mice over 4 weeks. In addition, we used two plants (Thymus vulgaris, Zingiber officinale) and one drug (cyproheptadine) to compare their effect with the effect of sweeteners. 


\section{Materials and Methods}

\section{Aqueous plants extracts preparation}

One hundred grams of leaves were mixed with 1 liter of distilled water and were heated for 4 hours. After cooling, the extract was filtered by using filter paper. The filtrate was collected, evaporated under vacuum and stored at $4{ }^{\circ} \mathrm{C}$ for a week. Finally, the plant extract dried using a freezing dryer to obtain a dry extract. ${ }^{7,8}$

\section{Thymus vulgaries oil extraction: simple hydro-distillation}

About $100 \mathrm{~g}$ of Thymus vulgaries dried leaves were added to $500 \mathrm{~mL}$ distilled water in a round-bottom flask. The leaves were mixed with about $500 \mathrm{~mL}$ of distilled water. The mixture was allowed to boil for $120 \mathrm{~min}$ at $100^{\circ} \mathrm{C}$. Volatile oils were collected into a clean beaker (this procedure was repeated three times). The isolated volatile oil was chemically dried using $\mathrm{CaCl}_{2}$ and stored in tightly-closed amber-colored bottles at $4{ }^{\circ} \mathrm{C} .9,10$

\section{Zingiber officinale oil extraction}

A total of $100 \mathrm{~g}$ of the powdered plants was weighed and then exhaustively extracted by mixing $400 \mathrm{~mL}$ of $50 \%$ ethanol with 200 $\mathrm{mL}$ of hexane in triple distilled water. ${ }^{11}$ The mixture was shaken for 72 hours using a shaker which adjusted at $200 \mathrm{rpm}$ at room temperature. Afterward, the mixture was filtered using suction flask and Buchner funnel filtration. The obtained filtrate representing the organic phase and aqueous phase was placed in a separator funnel for obtaining two separated layers; the upper one represented organic phase which containing the plant oil and the lower layer which represented the aqueous phase. The organic phase was placed in the rotary evaporator for 1 hour at $40^{\circ} \mathrm{C}$ to evaporate organic solvents and completely dried oils were obtained and then stored at $25^{\circ} \mathrm{C}$ till use. The remaining solid material was re-extracted again in $50 \mathrm{~mL}$ hexane and $125 \mathrm{~mL}$ of $50 \%$ ethanol in triple distilled-water and the same steps were carried out as mentioned above.

\section{Mice and study design}

Twenty-four mice aged around 5 weeks old weighing 24-30 g were housed 3 per cage with wood chip bidding and provided with normal food. The room temperature was maintained at $22-25^{\circ} \mathrm{C}$ and

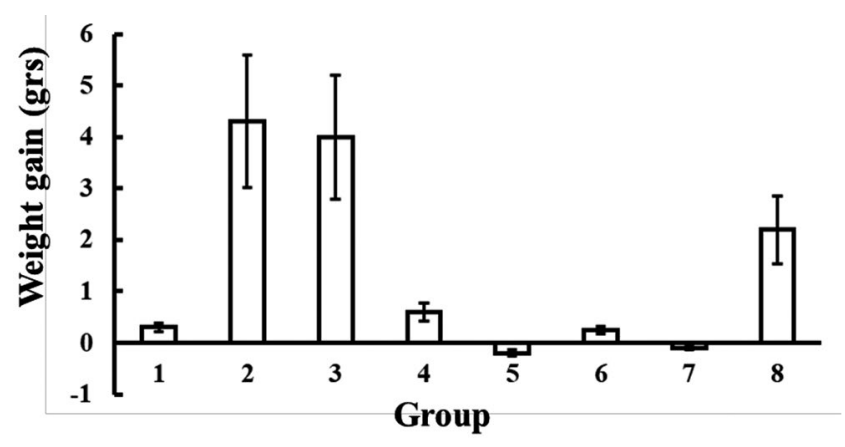

Figure 1. The body weight gains of mice fed with different treatment. Group 1 was the control group; group 2 received of Thymus vulgaries aqueous dry extract; group 3 received Thymus vulgaries oil extract; group 4 received Zingiber officinale aqueous extract; group 5 received Zingiber officinale oil extract; group 6 received aspartame solution; group 7 received saccharin solution. the humidity at 40-60\%. Each experimental group was fed with a specific solution preparation: group 1 (control group) received water in free access; group 2 received solution of Thymus vulgaries aqueous dry extract as appetizer plant with effective dose, 5000 $\mathrm{mg} / \mathrm{kg} / \mathrm{d} ;{ }^{12}$ group 3 received Thymus vulgaries oil extract, 1000 $\mathrm{mg} / \mathrm{kg} / \mathrm{d}$ that completely dispersed in $250 \mathrm{~mL}$ water; ${ }^{13}$ group 4 received Zingiber officinale aqueous extract, $200 \mathrm{mg} / \mathrm{kg} / \mathrm{d}$; group 5 received Zingiber officinale oil extract, $62.5 \mathrm{mg} / \mathrm{kg} / \mathrm{d}$, to decrease appetite; ${ }^{14}$ group 6 received aspartame solution of Acceptable Daily Intake (ADI) according to FDA, $50 \mathrm{mg} / \mathrm{kg} / \mathrm{d} ;{ }^{15}$ group 7 received saccharin solution of ADI, $15 \mathrm{mg} / \mathrm{kg} / \mathrm{d}$; group 8 received Cyproheptadine, which is used as appetite stimulant drug. ${ }^{16}$ The body weight and food consumption measured once a week and fluid intake measured twice a week. The experiment duration was 4 weeks and all analyses were done by using SPSS 21.0 and the Pvalue $<0.05$ were accepted as statistically significant.

\section{Results}

The effect of AS on appetite and subsequently food intake, liquid intake and weight changes was investigated. On parallel, the effect of Thymus vulgaris extracts, Zingiber officinale extracts and cyproheptadine on food intake, liquid intake and weight changes were also studied. All treated groups were compared to the control group fed on the same food and water. Both the aqueous extracts and oil extracts of Thymus vulgaris and Zingiber officinale were prepared and their effect on food intake, liquid intake and weight changes was studied.

The mean body weight of mice fed with AS, aspartame and saccharin, and cyproheptadin were studied. The control mice, mice receiving aspartame and cyproheptadine gain weight by $0.31 \mathrm{~g}$, $0.26 \mathrm{~g}$ and $2.17 \mathrm{~g}$ respectively, while mice that received saccharine lost $0.12 \mathrm{~g}$ from their main body weight (Figure 1 ). The mean body weight of mice receiving plant extracts, Zingiber officinale and Thymus vulgaries were studied. Mice received Thymus vulgaries aqueous extract and Thymus vulgaries oil extract gained $4.37 \mathrm{~g}$ and 3.99 g respectively. On the other hand, mice receiving Zingiber officinale aqueous extracts gained $0.6 \mathrm{~g}$, while mice receiving Zingiber officinale oil extract lost weight by $0.2 \mathrm{~g}$.

The mean food intake of mice received AS, aspartame and saccharin, and cyproheptadin were studied. The consumption of food of control mice and mice receiving aspartame and cyproheptadine was $109 \mathrm{~g}, 120 \mathrm{~g}$ and $107 \mathrm{~g}$ respectively, while mice that received saccharine consumed $117 \mathrm{~g}$ food (Figure 2). The mean food intake of mice receiving plant extracts, Zingiber officinale and Thymus vulgaries were studied. Mice received Thymus vulgaries aqueous extract and Thymus vulgaries oil extract consumed 116 and $103 \mathrm{~g}$ of food respectively. On the other hand, mice receiving Zingiber officinale aqueous extracts or Zingiber officinale oil extract consumed each $92 \mathrm{~g}$ food.

The mean fluid intake of mice received AS, aspartame and saccharin, and cyproheptadin were studied. The control mice, mice receiving aspartame and cyproheptadine consume $142 \mathrm{~mL}, 86 \mathrm{~mL}$, and $120 \mathrm{~mL}$ fluid respectively, while mice that received saccharine consume $105 \mathrm{~mL}$ fluid (Figure 3). The mean fluid intake of mice receiving plant extracts, Zingiber officinale and Thymus vulgaries were studied. Mice received Thymus vulgaries aqueous extract and Thymus vulgaries oil extract consumed $161 \mathrm{~mL}$ and $112 \mathrm{~mL}$ fluid respectively. On the other hand, mice receiving Zingiber officinale aqueous extracts and Zingiber officinale oil extract consumed 73 $\mathrm{mL}$ and $99 \mathrm{~mL}$ fluid respectively. 


\section{Discussion}

Various artificial sweeteners have been invented to replicate the sweet taste of sugar.

As they're virtually calorie-free, they're often marketed as weight loss friendly. Though AS provide sweet taste, many researchers believe that the lack of calories prevents complete activation of the food reward pathway. This may be the reason that AS are linked to increased appetite and cravings for sugary food in some studies. ${ }^{17}$ However, in other studies, AS did not affect appetite or calorie intake from other foods. ${ }^{18,19}$ In this study, we examined the effects of AS, saccharine and aspartame, administration on body weight, fluid intake, and food intake. The effect of natural products, Zingiber officinale and Thymus vulgaries, and a pharmaceutical product, cyproheptadine, were used as a comparison set with the AS.

Mice fed with AS showed no change in body weight gain, food intake or liquid intake. A previous study reported that the consumption of sweeteners resulted in significantly increased

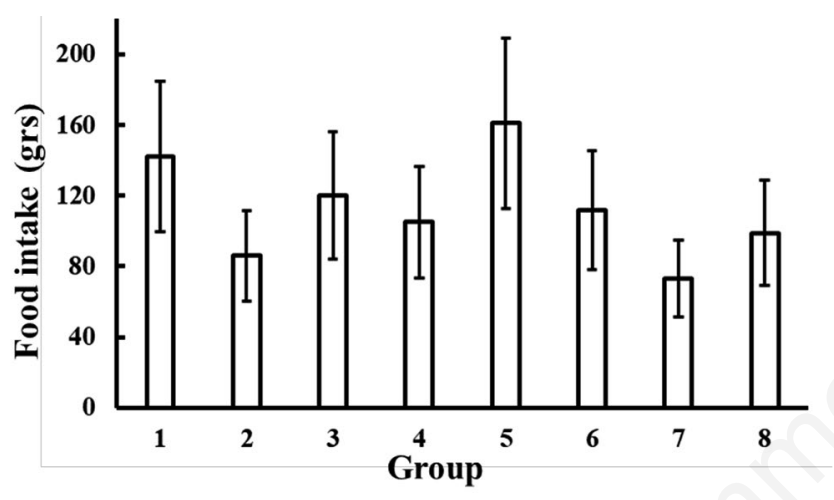

Figure 2. The food intake of mice fed with different treatment. Group 1 was the control group; group 2 received of Thymus vulgaries aqueous dry extract; group 3 received Thymus vulgaries oil extract; group 4 received Zingiber officinale aqueous extract; group 5 received Zingiber officinale oil extract; group 6 received aspartame solution; group 7 received saccharin solution.

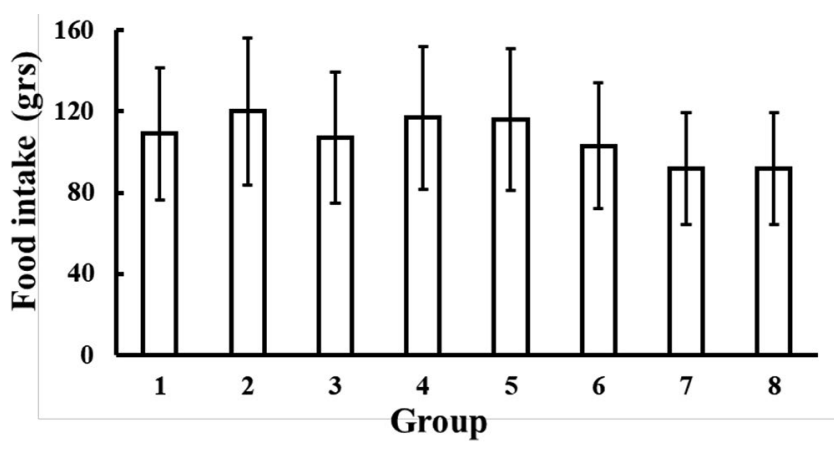

Figure 3. The fluid intake of mice fed with different treatment. Group 1 was the control group; group 2 received of Thymus vulgaries aqueous dry extract; group 3 received Thymus vulgaries oil extract; group 4 received Zingiber officinale aqueous extract; group 5 received Zingiber officinale oil extract; group 6 received aspartame solution; group 7 received saccharin solution. body weight; however, the food intake did not change. ${ }^{16}$ These results question the effect of non-caloric AS on weight-maintenance or body weight decrease. Observed associations between consumption of diet foods and obesity have sparked controversy over whether AS may promote weight gain, despite their negligible energy contribution. ${ }^{20}$ However, on a metabolic level, there are no data indicating that intrinsic properties of non-caloric AS modify energy balance independently of their influence on energy intake. ${ }^{6}$ The AS did not affect appetite or calorie intake from other foods and this is in agreement with other studies. ${ }^{18,19}$

Mice treated with Thymus vulgaries demonstrate superior estimates to body weight with more than 4-5grs. Mice treated with both, water and oil extract, of Thymus vulgaries, showed this significant increase in body weight. These mice didn't show significant differences in the food and fluid intake in comparison with other groups. Such improvement can be attributed to the beneficial effects of Thymus vulgaries active substances on the digestion of the food, the microbial balance of the intestine and the stimulation of the digestive enzymes. ${ }^{21}$ Our results are in agreement with other results showing that Thymus vulgaries supplementation of the diet resulted in a significant increase in body weight and caused the increased body weight gain, ${ }^{22}$ while other studies claimed the opposite by demonstrating that no significant effect was recorded. ${ }^{23}$ Zingiber officinale extract (water or oil) resulted in insignificant change in body weight gain. Many studies showed treatment with Zingiber officinale produces significant reduction in body weight. ${ }^{24,25}$ It was reported that the active ingredients of Zingiber officinale lower plasma lipids and body weight significantly, eventually preventing development of coronary artery disease in primary and secondary hyperlipidemic patients. ${ }^{26}$ Although, the food and fluid intake by mice fed with Zingiber officinale did not change in comparison with the control group. This shows that Zingiber officinale could modulate obesity through various potential mechanisms including increasing thermogenesis, increasing lipolysis, suppression of lipogenesis, inhibition of intestinal fat absorption ${ }^{14}$ but not the appetite. The appetite stimulating action and the weight gaining potential of mice treatment with cyproheptadine was studied. Insignificant change in food and fluid intake between the control group and mice treated with cyproheptadine. Although, mice treated with cyproheptadine showed significant increase in body weight. Cyproheptadine appears to be a safe, generally well-tolerated medication that has utility in helping facilitate weight gain. ${ }^{27}$ The present study shows that this weight gain in mice might principally due to decrease in activity resulting from the sedative effect of the drug. ${ }^{28}$

\section{Conclusions}

While people often choose diet or low-calorie products to lose weight, some studies suggest that AS may contribute to weight gain. In the present study, we tried to examine this hypothesis in vivo by administration of AS to the mice orally. As mentioned on the result the consumption AS has no significant effect on body weight.

\section{References}

1. WHO. Guideline: sugars intake for adults and children. Geneva: World Health Organization; 2015. Available from: https://www.who.int/news/item/04-03-2015-who-calls-on- 
countries-to-reduce-sugars-intake-among-adults-and-children

2. Tandel KR. Sugar substitutes: Health controversy over perceived benefits. Journal of pharmacology \& pharmacotherapeutics. 2011;2:236-43.

3. Chattopadhyay S, Raychaudhuri U, Chakraborty R. Artificial sweeteners - a review. J Food Sci Technol 2014;51:611-21.

4. Brauer P, Gorber SC, Shaw E, et al. Recommendations for prevention of weight gain and use of behavioural and pharmacologic interventions to manage overweight and obesity in adults in primary care. Canadian Med Assoc J 2015;187:184-95.

5. Swithers SE, Martin AA, Davidson TL. High-intensity sweeteners and energy balance. Physiol Behav 2010;100:55-62.

6. Mattes RD, Popkin BM. Nonnutritive sweetener consumption in humans: effects on appetite and food intake and their putative mechanisms. Am J Clin Nutr 2009;89:1-14.

7. Bandar H, Hijazi A, Rammal H, et al. Techniques for the extraction of bioactive compounds from Lebanese Urtica Dioica. Am J Phytomed Clin Ther 2013;1:507-13.

8. Dahiru D, Onubiyi J, Umaru HA. Phytochemical screening and antiulcerogenic effect of Moringa oleifera aqueous leaf extract. Afr J Trad Complement Altern Med 2006;3:70-5.

9. Huzar E, Dzięcioł M, Wodnicka A, et al. Influence of hydrodistillation conditions on yield and composition of coriander (Coriandrum sativum L.) Essential oil. Polish J Food Nutr Sci 2018;68:243-50.

10. Arora R, Singh B, Vig AP, Arora S. Conventional and modified hydrodistillation method for the extraction of glucosinolate hydrolytic products: a comparative account. SpringerPlus 2016;5:479.

11. Sattar N, Hussain F, Iqbal T. Antioxidant activities of Z. officinale Roscoe and A. allughas Roscoe (Zingiberaceae) Rhizomes. Bangladesh J Sci Industrial Res 2013;48:115-8.

12. Toghyani M, Tohidi M, Gheisari AA, Tabeidian SA. Performance, immunity, serum biochemical and hematological parameters in broiler chicks fed dietary thyme as alternative for an antibiotic growth promoter. Afr J Biotechnol 2010;9:6819-25.

13. Hippenstiel F, Abdel-Wareth A, Kehraus S, Südekum K. Effects of selected herbs and essential oils, and their active components on feed intake and performance of broilers-a review. Archiv fur Geflugelkunde 2011;75:226-34.

14. Ebrahimzadeh Attari V, Malek Mahdavi A, Javadivala Z, et al. A systematic review of the anti-obesity and weight lowering effect of ginger (Zingiber officinale Roscoe) and its mechanisms of action. Phytother Res 2018;32:577-85.
15. Food and Drugs Administration. Additional information about high-intensity sweeteners permitted for use in food in the United States. FDA; 2018

16. Polyak E, Gombos K, Hajnal B, et al. Effects of artificial sweeteners on body weight, food and drink intake. Acta Physiologica Hungarica 2010;97:401-7.

17. Yang Q. Gain weight by "going diet?" Artificial sweeteners and the neurobiology of sugar cravings: Neuroscience 2010. Yale J Biology Med 2010;83:101-8.

18. Anton SD, Martin CK, Han H, et al. Effects of stevia, aspartame, and sucrose on food intake, satiety, and postprandial glucose and insulin levels. Appetite 2010;55:37-43.

19. Peters JC, Wyatt HR, Foster GD, et al. The effects of water and non-nutritive sweetened beverages on weight loss during a 12 week weight loss treatment program. Obesity 2014;22:1415-21.

20. Mosdol A, Vist GE, Svendsen C, et al. Hypotheses and evidence related to intense sweeteners and effects on appetite and body weight changes: A scoping review of reviews. PloS One 2018;13:e0199558.

21. Langhout P. New additives for broiler chickens. World Poultry 2000;16:22-7.

22. Hassan FAM, Awad A. Impact of thyme powder (Thymus vulgaris L.) supplementation on gene expression profiles of cytokines and economic efficiency of broiler diets. Environ Sci Pollut Res 2017;24:15816-26.

23. Kamali Sangani A, Masoudi AA. The effects of herbal plants on Mucin 2 gene expression and performance in ascetic broilers. Iranian J Vet Med 2014;8:47-52.

24. Goyal RK, Kadnur SV. Beneficial effects of Zingiber officinale on goldthioglucose induced obesity. Fitoterapia 2006;77:160-3.

25. Leal DT, Fontes GG, Villa JKD, et al. Zingiber officinale formulation reduces hepatic injury and weight gain in rats fed an unhealthy diet. Anais da Academia Brasileira de Ciencias 2019;91:e20180975.

26. Murad S, Shaheena BJ, Niaz K, Aslam H. Zingiber Officinale: A Miraculous Plant Working As Therapeutic Agent. Life Sci J 2019;16.

27. Lemoine A, Harbison MD, Salem J, et al. Effect of Cyproheptadine on Weight and Growth Velocity in Children With Silver-Russell Syndrome. J Ped Gastroenterol Nutr 2018;66:306-11.

28. Harrison ME, Norris ML, Robinson A, et al. Use of cyproheptadine to stimulate appetite and body weight gain: A systematic review. Appetite 2019;137:62-72. 